\title{
Atividades em sala de aula
}

Ruth Ribas Itacarambi

Doutora pela Faculdade de Educação da Universidade de São Paulo (USP). Educadora aposentada do Instituto de Matemática e Estatística da USP. Coordenadora do Grupo Colaborativo de Investigação em Educação Matemática. Professora do curso de pós-graduação da Faculdade Oswaldo Cruz. Membro da Equipe SiteEducacional.

E-mail: acarambi@alumni.usp.br

Toda pessoa tem direito à educação [...]. A educação deve ser gratuita, pelo menos nos graus elementares e fundamentais. A instrução elementar será obrigatória.

$O$ ensino técnico e profissional deve ser generalizado. $O$ acesso ao ensino superior deve ser igualmente acessivel a todos, em função do mérito (artigo 26). ${ }^{1}$

As atividades nessa edição têm como cenário a pandemia que atinge o nosso país de forma incontrolável, com medidas sanitárias e econômicas que acirraram as diferenças sociais que já são grandes. O problema é a negação da ciência pelo governo federal. Vamos abordar este tema e as consequências dessa negação, a partir da reflexão em três artigos que, apesar de terem sido escritos antes dessa crise sanitária, trazem pontos significativos para a análise.

O primeiro que selecionamos é o artigo que apresenta a entrevista de Marco Antônio Rodrigues Dias, autor da obra "Ensino superior como bem público - perspectivas para o centenário da Declaração de Córdoba”, e traz em sua análise a questão que já vinha sendo anunciada, o ensino público. O entrevistado apresenta a educação superior como bem público e, também, pondera sobre as forças operantes nos últimos anos no modelo privado de ensino universitário no Brasil.

O compromisso com a transparência das informações, em particular, do conhecimento científico, é contemplado no artigo de Ana Beatriz Camargo Tuma e André Chaves de Melo Silva: "Transferência de conhecimentos para a sociedade: o caso do Instituto Nacional de Ciência e Tecnologia Biodiversidade e Produtos Naturais"2 que, segundo os autores, devem, dentre outros aspectos, contemplar a área de Transferência de conhecimentos para a sociedade, a qual, em linhas gerais, é voltada para a educação e a divulgação científica.

O ensino remoto, que é o cotidiano de nossas escola públicas e privadas, no momento atual, é discutido a partir do artigo de Thiago de Tavares das Neves e Elizama das Chagas Lemos: "Educar na era digital: considerações sobre tecnologia, conexões e educação a distância”, cujo objetivo é problematizar a

1.ONU - ORGANIZAÇÃO DAS NAÇÕES UNIDAS. Declaração universal dos direitos humanos. Artigo $26^{\circ}$. Brasília, DF, 2020. Disponivel em: https:// brasil.un.org/sites/default/ files/2020-09/por.pdf. Acesso em: 8 out. 2020.

2.Uma versão preliminar deste artigo foi apresentada no Grupo Temático Meio Ambiente: educomunicação, por e pela natureza, na Escola de Comunicação e Artes da Universidade de São Paulo, São Paulo, SP, de 12 a 14 de novembro de 2018. 
técnica, a tecnologia e as conexões com intuito de refletir sobre a importância desses três tópicos na construção de uma aposta de aprendizado, a educação a distância (EAD).

Como contraponto temos o artigo: "Sem modo avião: jovens e leitura de livros, hoje”, de Ana Elisa Ribeiro, com base em uma concepção de leitura como prática social e inspirado em estudos de história cultural e teorias de letramento, este trabalho traz uma discussão sobre a relação de jovens estudantes de ensino médio com as práticas de leitura, especialmente em relação aos dispositivos mais empregados para o porte e a leitura de textos.

As atividades nesta edição estão organizadas nos seguintes temas:

- A educação superior como bem público: educação superior como bem público, acessível a todos, livre e responsável e vinculada à solução dos problemas da sociedade em seu conjunto; entrevista com o autor de: "Ensino superior como bem público - perspectivas para o centenário da Declaração de Córdoba”.

- Transferência de conhecimentos para a sociedade: Transferência de conhecimentos para a sociedade: o caso do Instituto Nacional de Ciência e Tecnologia Biodiversidade e Produtos Naturais.

- Educar na era digital: Educar na era digital: considerações sobre tecnologia, conexões e educação a distância.

- Sem modo avião: Uma concepção de leitura como prática social.

\section{PRIMEIRA ATIVIDADE}

\section{A educação superior como bem público}

A atividade está organizada para os cursos de graduação, pós-graduação e professores das diferentes áreas do conhecimento, tem como apoio a entrevista do Prof. Dr. Marco Antônio Rodrigues Dias, professor Aposentado da Universidade de Brasília (UnB), Dias é ex-diretor da Divisão da Educação Superior da Organização das Nações Unidas para Educação, Ciência e Cultura (Unesco) em Paris (1981-1999). Nesta entrevista, apresenta o ponto de vista internacional sobre a educação, a partir de suas funções em diversos órgãos internacionais que, com Rafael Guarga, recebeu, em Córdoba, a distinção “Centenário da Reforma Universitária” por serem considerados, os dois, representantes atuais do espírito da reforma que marcou o conjunto do sistema universitário do continente: educação superior como bem público, acessível a todos, livre e responsável e vinculada à solução dos problemas da sociedade em seu conjunto.

Para o desenvolvimento da atividade propomos a seguinte sequência didática: 
1. Leitura do artigo, tendo como roteiro a discussão das questões:

- As propostas governamentais atuais de alterações no modelo de financiamento público do ensino superior brasileiro que trazem, em si, uma concepção bem diferente da educação como um bem público.

- A crise orçamentária do ensino superior brasileiro ganhou contornos dramáticos em 2019, quando o chamado "Future-se", projeto proposto pelo Ministério da Educação (MEC), apontou para uma mudança profunda no modelo de financiamento das universidades públicas federais.

- Qual é a avaliação do entrevistado sobre a proposta "future-se" apresentada em 2019 pelo MEC.

- Por que, na opinião do entrevistado, os atuais administradores do país decidiram pela privatização das instituições públicas.

2. Fazer a síntese das considerações em grupo. Nos mesmos grupos, solicitar que pesquisem no artigo as frases abaixo, contextualizando-as no texto e tendo como panorama o Brasil.

- As empresas, no regime capitalista, organizam-se para ter lucros.

- As universidades visam a objetivos sociais.

- Visar à eficácia é visto como sinônimo de lucro.

- Organizações internacionais decidiram destruir o conceito de educação como bem público.

- O contraditório é fundamental em uma democracia.

3. Após a discussão das considerações dos grupos, propor que pesquisem a produção acadêmica de sua instituição e as contribuições destas para o bem público.

4. Fazer o levantamento da composição social dos alunos de sua instituição, em especial, do papel das cotas na democratização do acesso ao ensino superior.

5. Discutir o significado dos gastos em educação, em ciência e tecnologia para o desenvolvimento e autonomia do conhecimento de uma nação livre e autônoma.

6. Pesquisar os gastos em ciência e tecnologia nas instituições internacionais que têm como compromisso o bem público.

\section{SEGUNDA ATIVIDADE}

\section{Transferência de conhecimentos para a sociedade}

$\mathrm{O}$ artigo que subsidia esta atividade é: "Transferência de conhecimentos para a sociedade: o caso do Instituto Nacional de Ciência e Tecnologia Biodiversidade e Produtos Naturais (INCT-BIONAT)”, de Ana Beatriz Camargo Tuma e André 
Chaves de Melo Silva. O artigo argumenta que os Institutos Nacionais de Ciência e Tecnologia (INCTs) devem, dentre outros aspectos, contemplar a área de "transferência de conhecimentos para a sociedade", a qual, em linhas gerais, é voltada para a educação e a divulgação científica.

A atividade está organizada na reflexão sobre a transparência da informação do conhecimento para a sociedade, e propomos a sequência didática:

1. Leitura do artigo com ênfase nos itens:

- Conhecer o INCT-BioNat, destacando: formado por 50 pesquisadores pertencentes a 16 universidades do Brasil e dois institutos de pesquisa.

- Rede de pesquisas interdisciplinares em química de produtos naturais provenientes da biodiversidade brasileira

- A missão da rede BioNat, destacando: disseminar o conhecimento produzido sobre produtos naturais para a sociedade.

2. Após esta leitura de identificação do INCT-BioNat, consultar o site do BioNat, que trata da missão.

3. Discutir, em pequenos grupos, o significado da educação ambiental, para subsidiar a discussão e fazer a leitura do item 3. Educação, comunicação e jornalismo ambiental.

4. Como fechamento da discussão, propomos a manifestação dos grupos sobre a afirmação das autoras no item conclusões: "Além disso, é possível afirmar que o INCT-BioNat produz comunicação ambiental e não jornalismo ambiental".

5. Ainda na perspectiva da transparência da informação cientifica para a sociedade, propomos que os grupos pesquisem, nas mídias sociais, a transparência sobre os dados da pandemia em nosso país (abril e maio de 2020) e relatem o significado disso para a preservação da saúde da população.

\section{TERCEIRA ATIVIDADE}

\section{EDUCAR NA ERA DIGITAL}

A escolha do artigo: "Educar na era digital: considerações sobre tecnologia, conexões e educação a distância”, de Ana Beatriz Camargo Tuma e André Chaves de Melo Silva, está relacionada com o momento que atravessamos em plena pandemia. Com a escola funcionando em conexão remota, cabe a questão da democratização do acesso à educação. O objetivo do artigo é problematizar a técnica, a tecnologia e as conexões com intuito de refletir sobre a importância desses três tópicos na construção de uma aposta de aprendizado, a educação a distância. Para a reflexão colocamos, também, a questão da desigualdade de 
acesso à tecnologia, da maioria dos jovens da escola pública, para continuar sua educação via conexão remota.

A reflexão sobre a questão da democratização e acesso à educação é destinada aos professores da escola básica, alunos, pais e alunos dos cursos de graduação, e está organizada na seguinte sequência didática:

1. Os participantes, em grupos da comunidade ou individualmente, coletam depoimentos de como é a participação dos alunos nas aulas remotas em sua região, completando com o número de quantos não conseguem participar por motivos de falta de equipamento: tablete, computador ou celular e falta de sinal da internet na região ou dificuldade de acessar o wi-fi.

2. Os grupos ou indivíduos apresentam suas informações nas suas redes de contato e discutem possíveis interferências para minorar os efeitos da desigualdade na população de jovens com dificuldade de acesso às tecnologias.

3. Aos alunos de graduação sugerimos a leitura do artigo, enfatizando os pontos a seguir, retirados do texto:

- É preciso enxergar na técnica moderna seu potencial libertário, sua potência criadora.

- Ao partir do pressuposto teórico de Latour ${ }^{3}$, as palavras social e conexão possuem o mesmo significado.

- A Educação a Distância (EAD) é uma modalidade de ensino eficiente e eficaz em contemplar grandes contingentes de pessoas de forma efetiva.

- De acordo com Blois ${ }^{4}$ o Brasil tem como característica ser um espaço democrático de convivência de ofertas de EAD e, dessa forma, propicia o atendimento aos excluídos.

- O aumento do uso das Tecnologias Digitais de Informação e Comunicação (TDIC) estão criando ambientes de interação e de aprendizagem.

- O conceito de conectivismo se encaixa de forma adequada nesse processo de troca na era digital.

4. Após a leitura sugerimos a discussão desses pontos, primeiro contextualizando-os no texto e depois a opinião do grupo ou indivíduo sobre cada afirmação.

5. Comparar as afirmações dos autores com a realidade da escola pública apresentada nas mídias, nesse momento de pandemia, com a conexão remota.

6. Discutir o significado de ensino remoto verso educação a distância (EAD), a quem interessa a qualidade do ensino e aprendizagem. Para subsidiar propomos consultar o site do Conselho Nacional de Secretários de Educação ${ }^{5}$ e a leitura no artigo sobre AVAs no último parágrafo do item: ambientes diferenciados de aprendizagem.
3.LATOUR, Bruno. Reagregando o social: uma introdução à teoria do Ator-Rede. Salvador: Edufba, 2012; Bauru: Edusc, 2012.

4.BLOIS, Marlene. Do ensino por correspondência à internet: a busca da democratização do conhecimento. Revista CREAD, State College, v. 8, p. 29-38, 2000.

5.ENSINO remoto. Consed.info. Brasília, DF, 20 maio 2020. Disponível em: https://consed.info/ ensinoremoto/. Acesso em: 8 out. 2020. 
comunicação \& educação • Ano XXV • número 1 • jan/jun 2020

\section{QUARTA ATIVIDADE \\ Sem modo avião: uma concepção de leitura como prática social}

O artigo de Ana Elisa Ribeiro: "Sem modo avião: jovens e leitura de livros, hoje" foi escolhido para a reflexão sobre a concepção da leitura como prática social, pois tem como objetivo tecer considerações sobre o modo como os jovens do ensino médio intercalam suas práticas de leitura em ambientes digitais e impressos. A atividade é destinada aos professores de português do ensino básico e a alunos de graduação de áreas afins. Está organizada na sequência didática a seguir:

1. Leitura individual do artigo, com destaque aos pontos que o leitor considerar significativo para sua prática em sala de aula.

2. Discussão, em grupo, dos destaques. Observação: o grupo pode ser dos professores da escola sobre como motivar os alunos para a leitura de textos literários ou dos alunos de graduação, nas suas aulas de prática de ensino sobre literatura.

3. Apresentamos alguns pontos selecionados para subsidiar a discussão nos grupos:

- O que está nas suas mochilas hoje.

- Nos deslocamentos pela cidade.

- Livros impressos e livros digitais.

- Em relação ao valor simbólico, o livro impresso continuou em primeiro lugar.

- Ler e pesquisar na web, boas e más aulas.

4. Sugerimos que os professores de português discutam, em suas redes de contatos, que práticas pedagógicas são possíveis para promover as leituras de textos literários por parte dos alunos em educação remota. 